04;14

\title{
Разработка и применение устройства генерации холодной плазмы атмосферного давления для лечения повреждений кожи и мягких тканей животных
}

(ㄷ) О.А. Емельянов ${ }^{1}$, Н.О. Петрова ${ }^{2,3}$, Н.В. Смирнова ${ }^{1,4}$, М.B. Шемет ${ }^{1}$

${ }^{1}$ Санкт-Петербургский политехнический университет Петра Великого, Санкт-Петербург

${ }^{2}$ Биотехнологическая компания „Биокад“, Санкт-Петербург

${ }^{3}$ КСК „Осиновая роща“, Санкт-Петербург

${ }^{4}$ Институт цитологии РАН, Санкт-Петербург

E-mail: oaemel2@gmail.com

Поступило в Редакцию 30 декабря 2016 г.

Описано устройство для получения холодной плазмы атмосферного давления в воздухе с использованием игольчатой системы электродов положительной полярности. Генерация плазмы обеспечивается развитием импульсного периодического разряда наносекундной длительности, амплитуда импульсов тока составляет 10-20 mA при характерных частотах $10-20 \mathrm{kHz}$ и уровнях приложенного напряжения $8-20 \mathrm{kV}$. Высокая эффективность разработанной методики подтверждается клиническими результатами лечения травматологических патологий крупных сельскохозяйственных животных.

DOI: $10.21883 /$ PJTF.2017.16.44930.16627

Получение и применение холодной плазмы атмосферного давления (cold atmospheric plasma, CAP) открыли в последние 5-10 лет новые горизонты использования плазмы в биологии и медицине. Отличительной особенностью холодной плазмы является низкая энергия электронов $(\sim 1-3 \mathrm{eV})$, при этом неравновесность плазмы характеризуется низкой температурой ионов и рабочего газа $\left(<40^{\circ} \mathrm{C}\right)$, что позволяет использовать плазму для воздействия непосредственно на живые клетки и ткани. Для биомедицинских приложений основными источ- 
никами генерации САР служат различные формы тлеющего разряда атмосферного давления: APGD (atmospheric pressure glow discharge), ВЧ-микроразряды (atmospheric-pressure RF plasma microdischarges), барьерные разряды (dielectric-barrier discharges) и коронные разряды (corona discharges) [1,2]. Основными факторами воздействия плазмы на объект являются электромагнитное поле, УФ-излучение, заряженные частицы (электроны и ионы) и активные нейтральные частицы. В воздушной среде генерируются главным образом активные формы кислорода и азота (reactive oxygen species, reactive nitrogen species), такие как перекись водорода $\left(\mathrm{H}_{2} \mathrm{O}_{2}\right)$, гидроксильные радикалы $\left(\mathrm{OH}^{-}\right)$, синглетный кислород $\left({ }^{1} \mathrm{O}_{2}\right)$, различные окислы азота $\mathrm{NO}, \mathrm{NO}_{2}$ и др.) [3]. Таким образом, эффекты применения САР обусловлены взаимодействием компонентов плазмы со специфическими структурными элементами и функциями живых клеток в системах как in vitro, так и in vivo. Свойства САР позволяют работать непосредственно с живой тканью (санировать раны, использовать этот подход для борьбы с патогенной микрофлорой в гинекологии, отоларингологии, стоматологии и др.). Доказанным преимуществом использования холодной плазмы в травматологии и хирургии является ее способность ускорять процесс образования кровяного сгустка, т.е. гемостатический эффект. Также показано, что плазменное воздействие стимулирует процессы тканевой регенерации путем активации иммунных клеток и фибробластов кожи. В результате этого увеличивается выработка коллагена, а также происходит уменьшение площади раны путем стягивания ее краев. В настоящее время доказано, что холодная плазма может эффективно применяться не только для бесконтактной стерилизации и ускорения заживления ран, но и при лечении рака (замедления роста опухолей и метастазирования) $[1,2,4]$. Данная область знаний является относительно новой. Например, число публикаций, посвященных плазменной обработке раковых опухолей, стало резко увеличиваться лишь в последние пять лет [4]. Все эти многочисленные эффекты делают возможным использование установок, генерирующих холодную плазму, в качестве эффективных реабилитационных средств при реконструкции сложных глубоких инфицированных дефектов кожи и мягких тканей (ран, свищей, трофических язв, открытых переломов), ожогов, кожных заболеваний (дерматитов, экзем, лишая).

Письма в ЖТФ, 2017, том 43, вып. 16 


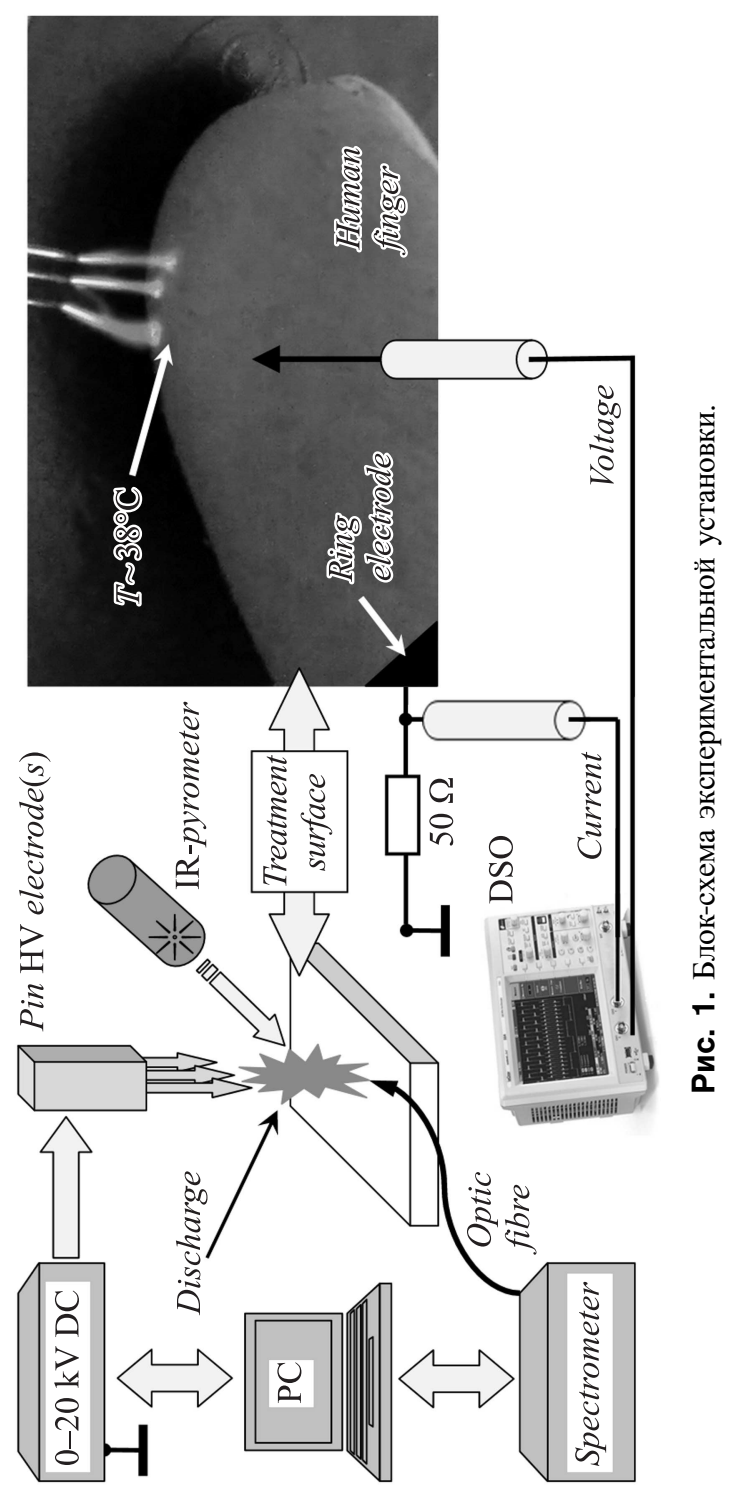

Письма в ЖТФ, 2017, том 43, вып. 16 
В отличие от ряда известных типов источников плазмы [5-7] в настоящей работе описан метод генерации САР в воздухе с использованием игольчатой системы электродов положительной полярности в условиях развития периодического разряда наносекундной длительности, при этом осуществляется непосредственное (прямое) воздействие плазмы на обрабатываемую поверхность. Упрощенная блок-схема экспериментальной установки представлена на рис. 1. Для реализации совместной генерации плазменных струй в случае многоигольчатых систем (рис. 1) учитывались особенности формирования многоострийного коронного разряда $[8]$.

Постоянное напряжение величиной $U=8-20 \mathrm{kV}$ прикладывалось к стальной игле (или системе игл) через высокоомное (> 50 M $\Omega$ ) балластное сопротивление. При этом касание иглой или генерируемой плазмой поверхности живого объекта было безопасным с точки зрения возможности поражения электрическим током. Радиус закругления игл составлял $\sim 40 \mu \mathrm{m}$. Генерация плазмы осуществлялась в результате развития импульсного стримерного разряда в воздушном зазоре $(d=3-10 \mathrm{~mm})$ между иглой и поверхностью обрабатываемого объекта. В процессе плазменной обработки осуществлялась регистрация разрядного тока $I_{d}$ с помощью малоиндуктивного шунта $50 \Omega$, подключенного последовательно с обрабатываемым объектом. Дополнительно определялось изменение потенциала $\varphi_{x}$ на поверхности обрабатываемого объекта в точках, находящихся на различном удалении $(x)$ от области касания разрядом поверхности объекта. Значения потенциала на шунте и поверхности объекта измерялись с помощью осциллографа LeCroy WJ-322 (2 GS/s). Следует отметить, что измерение потенциала поверхности объекта не оказывало существенного влияния на разрядный процесс.

На рис. 2 представлены типичные осциллограммы импульсов тока разряда $I_{d}$ и потенциала $\varphi_{x}=2 \mathrm{~mm}$ (в $2 \mathrm{~mm}$ от разряда) для случая одноигольчатой системы, $d=1 \mathrm{~cm}, U=15 \mathrm{kV}$, когда в качестве объекта обработки выступал палец человека. Из осциллограмм видно, что разряд имел периодический характер. В диапазоне исследуемой амплитуды прикладываемого напряжения $8-20 \mathrm{kV}$ частота процесса составляла $10-20 \mathrm{kHz}$, амплитуда разрядных импульсов тока $10-20 \mathrm{~mA}$, длительность полуширины импульсов 50-100 ns. Характеристики полученных импульсных разрядов близки к параметрам APGD, относительно недавно изученных в [9]. Контроль температуры объекта осуществлялся

3 Письма в ЖТФ, 2017, том 43, вып. 16 


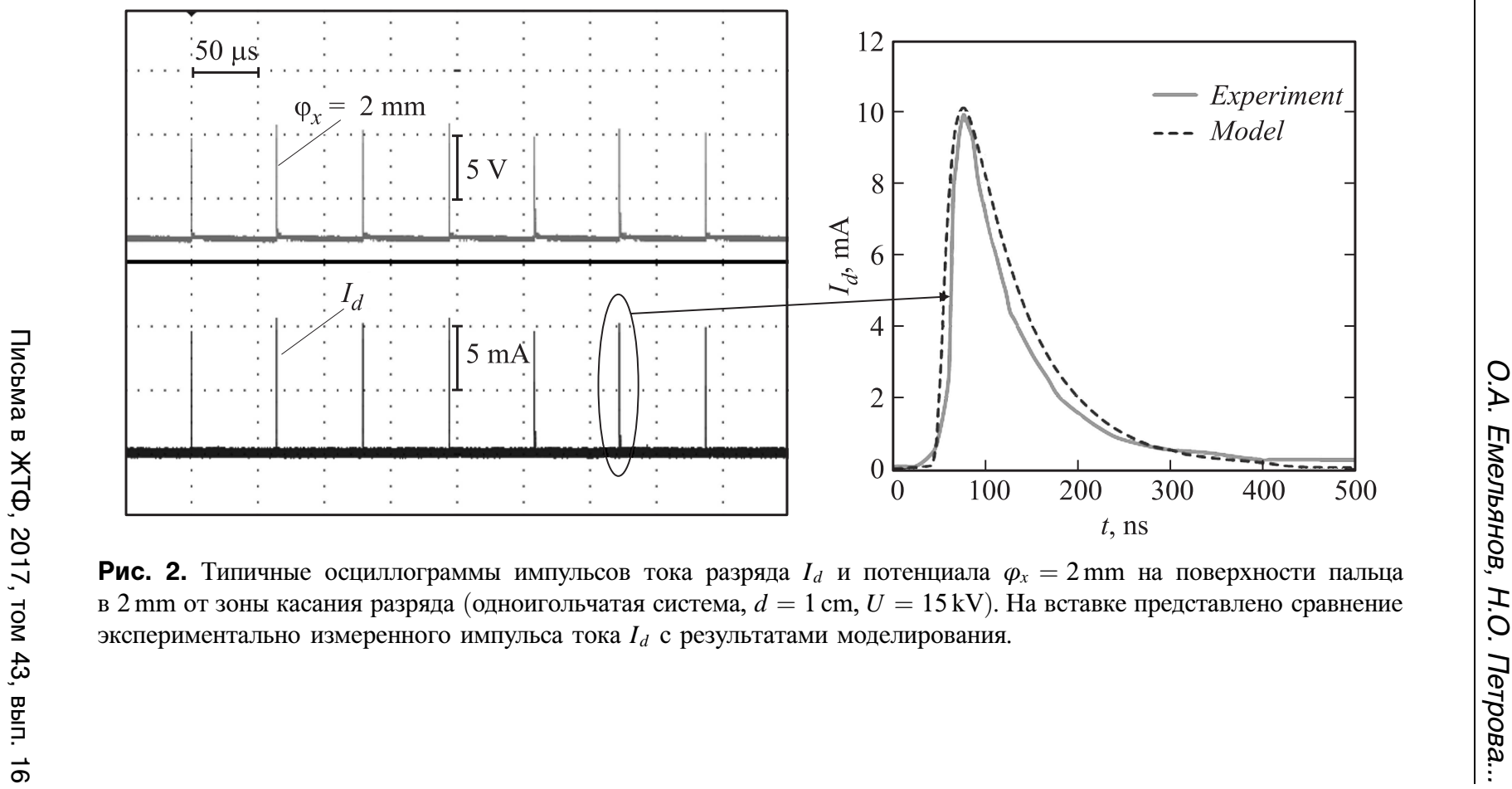


бесконтактно с помощью пирометра OPTRIS LaserSight, который характеризовался спектральным диапазоном измерения $8-14 \mu \mathrm{m}$, временем отклика $150 \mathrm{~ms}$ и размером зоны измерения $1 \mathrm{~mm}^{2}$. В зависимости от амплитуды и частоты импульсов разрядного тока температура поверхности находилась в диапазоне $35-80^{\circ} \mathrm{C}$. Исследование спектрального состава генерируемой плазмы производилось с помощью спектрометра Avantes AvaSpec-2048XL в диапазоне 200-1150 nm (оптическое разрешение не менее $0.2 \mathrm{~nm}$ ). В зарегистрированных спектрах наиболее интенсивные линии были обнаружены в диапазоне $300-400 \mathrm{~nm}$, что соответствует второй положительной системе азота $\mathrm{N}_{2}$.

Для моделирования исследуемого процесса была разработана эквивалентная схема замещения, учитывающая электрофизические параметры экспериментальной установки, разряда и объекта обработки. Частотные зависимости импеданса, полученные с помощью анализаторов иммитанса Hioki IM3570 и Hioki IM3533 в диапазоне $0.1 \mathrm{~Hz}-5 \mathrm{MHz}$, находились в хорошем согласии с известными литературными данными [10]. На вставке к рис. 2 представлено сравнение экспериментально измеренного импульса тока разряда $I_{d}$ с результатами моделирования.

Эффективность и удобство использования разработанной методики подтверждаются экспериментальными результатами при лечении травматологических патологий крупных сельскохозяйственных животных. В ветеринарии тема борьбы с патогенной микрофлорой при лечении хирургических патологий является даже более актуальной, чем в медицине человека. Зачастую применение антибиотиков при лечении животных связано с наступлением неблагоприятных побочных эффектов и даже летальностью. А в случае лечения ран в силу особенностей животных обработка ран и наложение повязок затруднены. В этом контексте особенно ценна технология, позволяющая не допустить инфицирования раны или в случае, если это произошло, быстро и эффективно санировать зону повреждения. Одновременно важно стимулировать процессы тканевой регенерации, добиться заживления максимально быстро, без патологических грануляции и рубцевания.

Для ограниченного клинического исследования были отобраны пять лошадей с повреждениями кожи и мягких тканей конечностей. Все клинические случаи характеризовались:

- значительным микробным загрязнением раны;

- значительным по размерам дефектом кожных покровов;

$3^{*}$ Письма в ЖТФ, 2017, том 43, вып. 16 
— наличием в ране гематомы;

- наличием некротических тканей;

- неблагоприятным общим состоянием организма.

Наблюдались низкие динамика и эффективность заживления с помощью традиционных способов лечения (местное применение антисептиков, наложение стерильных повязок с ранозаживляющими препаратами). Бактериологические посевы выявили, что раны были инфицированы золотистым стафилококком (Staphylococcus aureus), Staphylococcus epidermis, Enterococcus mundtii, кишечной палочкой (Escherichia coli), плесневыми грибами Aspergillus fumigatus и Rhizopus sp. Лечение ран с помощью проведения плазменной терапии осуществлялось раз в неделю в виде монотерапии (не использовались дополнительная местная обработка антисептиками и наложение стерильных повязок с ранозаживляющими препаратами). Продолжительность воздействия зависела от площади раневого дефекта, но не превышала 10-15 min. Для полного заживления ран было необходимо по два-три раунда терапии. Усредненные данные динамики лечения с помощью плазменной терапии свидетельствовали о полном отсутствии гнойных осложнений у животных начиная с первого раунда терапии. Первая неделя лечения характеризовалась очищением раны от гнойных масс и умеренной грануляцией, на второй неделе наблюдались процессы эпителизации и частичное смыкание краев раны, третья неделя характеризовалась полным заживлением ран.

За последние годы в литературе появилось достаточно много работ, описывающих применение холодной плазмы для решения медикобиологических задач. Однако бо́льшая их часть посвящена использованию холодной плазмы для воздействия на клетки in vitro (на различные штаммы бактерий, грибы и вирусы). Вместе с тем число исследований, демонстрирующих эффективность воздействия в рамках реальной сложной патологии, крайне мало. По мнению авторов, аналоги разработанного устройства генерации холодной плазмы в воздухе не применялись для лечения травматологических патологий крупных сельскохозяйственных животных. Применение разработанной методики обладает рядом преимуществ, к которым можно отнести безболезненность и атравматичность воздействия, значительное ускорение заживления операционных и травматических повреждений, практически полное отсутствие воспалительных процессов в обработанных плазмой ранах, отсутствие побочных эффектов.

Письма в ЖТФ, 2017, том 43, вып. 16 


\section{Список литературы}

[1] Kong M.G., Kroesen G., Morfill G. et al. // New J. Phys. 2009. V. 11. P. 115012 (1-35).

[2] Fridman A., Friedman G. Plasma Medicine. John Wiley \& Sons, 2013. 545 p.

[3] Sysolyatina E., Mukhachev A., Yurova M. et al. // Plasma Process. Polym. 2014. V. 11. P. $315-334$.

[4] Keidar M. // Plasma Sources Sci. Technol. 2015. V. 24. P. 033001 (1-20).

[5] Golda J., Held J., Redeker B. // J. Phys. D: Appl. Phys. 2016. V. 49. P. 084003 (1-11).

[6] Winter J., Brandenburg R., Weltmann K.-D. // Plasma Sources Sci. Technol. 2015. V. 24. P. 064001 (1-19).

[7] Соснин Э.А., Панарин В.А., Скакун В.С. и др. // ЖТФ. 2016. Т. 86. В. 5. C. $151-154$

[8] Pei X., Lu X., Liu J. et al. // J. Phys. D: Appl. Phys. 2012. V. 45. P. 165205 $(1-5)$.

[9] Pai D.Z., Lacoste D.A., Laux C.O. // J. Appl. Phys. 2010. V. 107. P. 093303 (1-15).

[10] Chen C., Liu D.X., Liu Z.C. et al. Plasma Chem. Plasma Process. 2014. V. 34. P. 403-441.

Письма в ЖТФ, 2017, том 43, вып. 16 